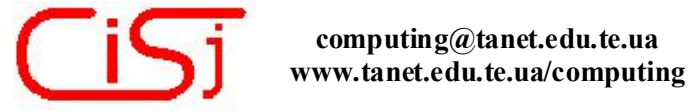

\title{
FUZZY NEURAL NETWORKS IN INTELLIGENT MANUFACTURING SYSTEMS
}

\author{
Galina Setlak
}

Rzeszow University of Technology Department of Computer Science

ul. W. Pola 2, 35-959 Rzeszyw Poland E-mail: gsetlak@prz.rzeszow.pl

\begin{abstract}
This paper presents fuzzy neural networks, which are an expansion of classical neural networks. These networks can formally represent and process both the qualitative (inguistic) and quantitative information, which usually describe a complex, multidimensional systems or decision making processes. The second part presents the results of tests and a practical implementation of applications for decision support systems based on fuzzy neural networks used for strategic management and determination of product development strategy.
\end{abstract}

Keywords: neural networks, fuzzy logic, fuzzy neural networks, decision support systems.

\section{INTRODUCTION}

Solving many problems concerned with modern manufacturing manage-ment is connected with processing of incomplete, inexact information. First of all, these problems are mainly as-pects of strategic management: mar-ket analysis, choice of product stra-tegy and of manufacturing system de-velopment, choice of strategy for ma-nufacturing arrangement, and others. To solve such tasks it is necessary to apply unstructured procedures for decision making, which use experi-mental data, skills and human intuition.

To model and process fuzzy, lin-guistic or so called qualitative infor-mation $[1,2,3]$ fuzzy sets theory and mathematical apparatus of fuzzy logic are used. In such systems of decision making support, the process of obtaining explanations and inference engine operationduring processing of fuzzy knowledge is highly compli-cated. While modeling real complex systems, additional difficulties ap-pear, which are connected with an increase in the number of the process and system parameters to be modeled, which causes a considerable increase in the dimensions of mathematical models and time needed for identi-fication and calculation of these parameters by a computer. Besides, in real systems, quantitative information is being processed together with qualitative information, too.

In this paper possibilities are presented of an approach which combines methods based on fuzzy logic and artificial neural networks, which results in creation of a structure called a fuzzy neural network. The structure of a fuzzy neural network combines the best properties of an artificial neural net- work, the ability to learn from examples, and fuzzy logic, i.e. conversion of fuzzy knowledge. On the basis of the results presented in this paper [1,2,3] it may be sup-posed that a fuzzy neural network is a more universal mathematical instru-ment, which can be used for the systems of decision making support in complex multidimensional systems for processing various types of information, both linguistic and quantitative.

Fuzzy neural networks presented in this paper are a generalization and expansion of classical neural net-works. These networks are able to process qualitative and linguistic information apart from quantitative information through the application of the fuzzy set theory and mechanisms of fuzzy decision making. In this paper the results of the tests and a practical implementation of appli-cations for decision support systems based on fuzzy neural networks used for strategic management and determination of product development strategy will be presented.

\section{BASIC DEFINITIONS. CLASSICAL ARTIFICIAL NEURAL NETWORK.}

The original source of fuzzy neural networks is a multilayer perceptron, which is a feedforward neural network characterized by transferring of information from the input level through $\mathrm{K}$ additional hidden layers to the output layer. Fig. 1 presents the structure of a two-layer perceptron, i.e. a perceptron with one additional (hidden) layer.

In the standard structure of a multilayer perceptron each $\mathrm{i}^{\text {th }}$ node in $\mathrm{k}^{\text {th }}$ layer is connected through synaptic weights $\mathrm{W}_{\mathrm{ij}}$ with all the nodes of the previous layer $(\mathrm{k}-1)$. 
Output signals are calculated as follows:

$Y_{i}^{\prime}=f\left(\sum_{j=1}^{N} W_{i j} X_{j}-q_{j}\right)-$ for hidden layer neurons

(1),

$Y_{i}=f\left(\sum_{j=1}^{N} W_{i j}^{\prime} Y_{i}^{\prime}-q_{j}\right)-$ for output layer neurons

(2),

where :

- $\mathrm{W}_{\mathrm{ij}}, \mathrm{W}_{\mathrm{ij}}$ - synaptic weights,

$\mathrm{f}\left(\sum_{\mathrm{j}=1}^{\mathrm{N}} \mathrm{W}_{\mathrm{ij}} \mathrm{Xj}_{\mathrm{j}}\right)-$ activation function.

- $\mathrm{q}_{\mathrm{j}}, \mathrm{q}_{\mathrm{j}}$ - shift values,

- $x_{i}(j=1,2, \ldots, N)$ - input signals.

In hidden perceptron layers transfor-mation of nonlinear information takes place. For processing of non-linearity in the hidden layers sigmoid function is often used, which can be described as fol-

lows: $\quad f(\alpha)=\frac{1}{1+e^{-\alpha}}$

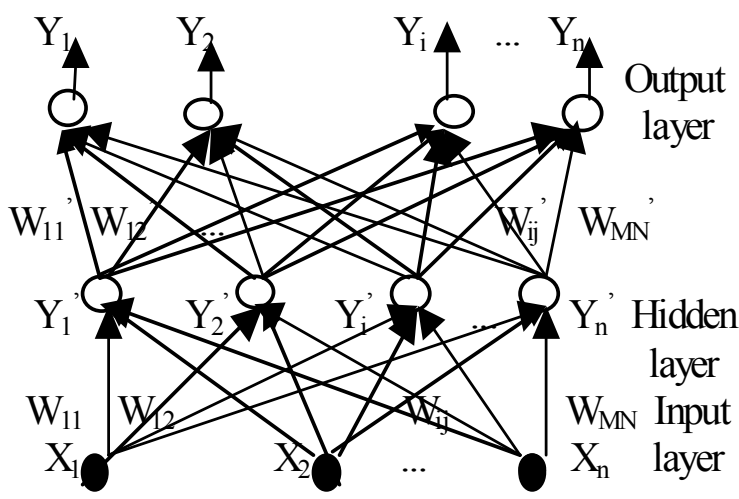

Fig. 1. Model of multilayer feedforlard perceptron

In practice, the main Back-Propagation algorithm, as well as its different modifications, is used for training neural networks of the multilayer perceptron type $[4,5]$. Details of the network training process will be presented in the further part of this paper concerned with fuzzy neural networks, which is the object of the research.

\section{MODEL OF A FUZZY NEURAL NETWORK}

Let us consider a system with $\mathrm{n}$ inputs: $\mathrm{x}_{1}, \mathrm{x}_{2}, \ldots$, $\mathrm{x}_{\mathrm{n}}\left(\mathrm{x}_{\mathrm{i}} \in \mathrm{X}_{\mathrm{i}}, \mathrm{i}=1,2, \ldots, \mathrm{n}\right)$ and $\mathrm{m}$ outputs: $\mathrm{y}_{1,} \mathrm{y}_{2}, \ldots, \mathrm{y}_{\mathrm{m}}$ $\left(y_{j} \in Y_{j}, j=1,2, \ldots, m\right)$, respectively, where

$\mathrm{x}=\left(\mathrm{x}_{1}, \mathrm{x}_{2}, \ldots, \mathrm{x}_{\mathrm{n}}{ }^{\mathrm{T}} \in \mathrm{X}_{1} \mathrm{x}_{2} \mathrm{X}_{2} \ldots \mathrm{x}_{\mathrm{n}}\right.$ and $\mathrm{y}_{\mathrm{j}} \in \mathrm{Y}_{\mathrm{j}}$ are linguistic variables. Qualitative information, which descri-bes the behavior of this system, is presented as a number of K fuzzy IF-THEN rules in the following form: $\left.\mathrm{A}_{\mathrm{n} 1}{ }^{\prime}\right)$

IF $\left(x_{1}\right.$ is $\left.A_{11}{ }^{\prime}\right)$ and $\left(x_{2}\right.$ is $\left.A_{21}{ }^{\prime}\right)$ and $\ldots$ and $\left(x_{n}\right.$ is $\operatorname{THEN}\left(\mathrm{y}_{1}\right.$ is $\left.\mathrm{B}_{11}\right)$ and ... and $\left(\mathrm{y}_{\mathrm{m}}\right.$ is $\left.\mathrm{B}_{\mathrm{ml}}\right)$ and ... and

IF $\left(x_{1}\right.$ is $\left.A_{1 k}{ }^{\prime}\right)$ and $\left(x_{2}\right.$ is $\left.A_{2 k}{ }^{\prime}\right)$ and ... and $\left(x_{n}\right.$ is $\left.\mathrm{A}_{\mathrm{nk}}{ }^{\prime}\right)$ THEN $\left(\mathrm{y}_{1}\right.$ is $\left.\mathrm{B}_{1 \mathrm{k}}{ }^{\prime}\right)$ and ... and $\left(\mathrm{y}_{\mathrm{m}}\right.$ is $\left.\mathrm{B}_{\mathrm{mk}}{ }^{\prime}\right)$, (4)

Where:

$\mathrm{A}_{\mathrm{ik}}{ }^{\prime}, \mathrm{B}_{\mathrm{jk}}{ }^{\prime},(\mathrm{i}=1,2, \ldots, \mathrm{n}),(\mathrm{j}=1,2, \ldots, \mathrm{m})$ and $(\mathrm{k}=$ $1,2, \ldots, \mathrm{k})$ are certain linguistic notions which des-cribe appropriate system inputs and outputs. $\mathrm{A}_{\mathrm{ik}}{ }^{\prime}$ and $\mathrm{B}_{\mathrm{jk}}{ }^{\prime}$ are fuzzy sets, where $\mathrm{A}_{\mathrm{ik}}{ }^{\prime} \in \mathrm{R}\left(\mathrm{X}_{\mathrm{i}}\right)$ and $\mathrm{B}_{\mathrm{jk}}{ }^{\prime} \mathrm{OR}\left(\mathrm{Y}_{\mathrm{j}}\right)$ and $\mathrm{R}\left(\mathrm{X}_{\mathrm{i}}\right)$ and $\mathrm{R}\left(\mathrm{Y}_{\mathrm{j}}\right)$ mean clusters of all fuzzy sets which are determined on the sets $\mathrm{X}_{\mathrm{i}}$ and $Y_{j}$, respectively.

Quantitative information that describes the behavior of the system may be presented as a number of $\mathrm{L}$ sets with numerical data of the following type:

$\left(\mathrm{x}_{11}^{\prime} \mathrm{x}_{21}, \ldots, \mathrm{x}_{\mathrm{nl}}{ }^{\prime}, \mathrm{y}_{11}^{\prime}, \mathrm{y}_{21}, \ldots, \mathrm{y}_{\mathrm{ml}}{ }^{\prime}\right)$, where $\mathrm{l}=1,2, \ldots, \mathrm{L}$, and $\left(\mathrm{x}_{\mathrm{il}} \mathrm{O} \mathrm{X}_{\mathrm{i}}\right),\left(\mathrm{y}_{\mathrm{j} 1} \mathrm{O} \mathrm{Y}_{\mathrm{j}}\right)$. Quantitative information may also be presented as a system of L conditional rules in the following form:

$$
\begin{aligned}
& \text { IF }\left(\mathrm{x}_{1}=\mathrm{x}_{11}^{\prime}\right) \text { and } \ldots . . \text { and }\left(\mathrm{x}_{\mathrm{n}}=\mathrm{x}_{\mathrm{n} 1}{ }^{\prime}\right) \text { THEN } \\
& \left(\mathrm{y}_{1}=\mathrm{y}_{11}\right) \text { and } \ldots \text { and } \\
& \left(\mathrm{y}_{\mathrm{m}}=\mathrm{y}_{\mathrm{ml}}\right)(1=1,2, \ldots, \mathrm{L})
\end{aligned}
$$

The methodology of processing the above-presented information (i.e. qua-litative, quantitative, and mixed) is based on the application of a fuzzy neural network. In accordance with the main idea the details of which are presented in papers [1,2,3], all types of the input information are as if «built into» the structure of a fuzzy neural network during the process of network training. Another important task is development of the inference engine, which will be able to generate responses of the system to the types of input data determined above. These problems according to the approach presented are solved in the following way: the input information and the corresponding output information is processed by means of two interfaces, which are developed on the basis of the fuzzy sets theory and fuzzy logic. These interfaces have the same structure.

The task of the interfaces is transformation of the input infor-mation to the form allowing for classical neural network processing.

For performing this task, let us deter-mine the following notions from the theory of fuzzy logic and fuzzy decision-making $[4,5]$ : 
- Membership function is a function which assigns a degree of membership (mostly, in the interval $[0,1])$ to the fuzzy set: $\mathrm{m}_{\mathrm{Aik}}\left(\mathrm{x}_{\mathrm{i}}\right), \mathrm{m}_{\mathrm{Ai}}\left(\mathrm{x}_{\mathrm{i}}\right)$

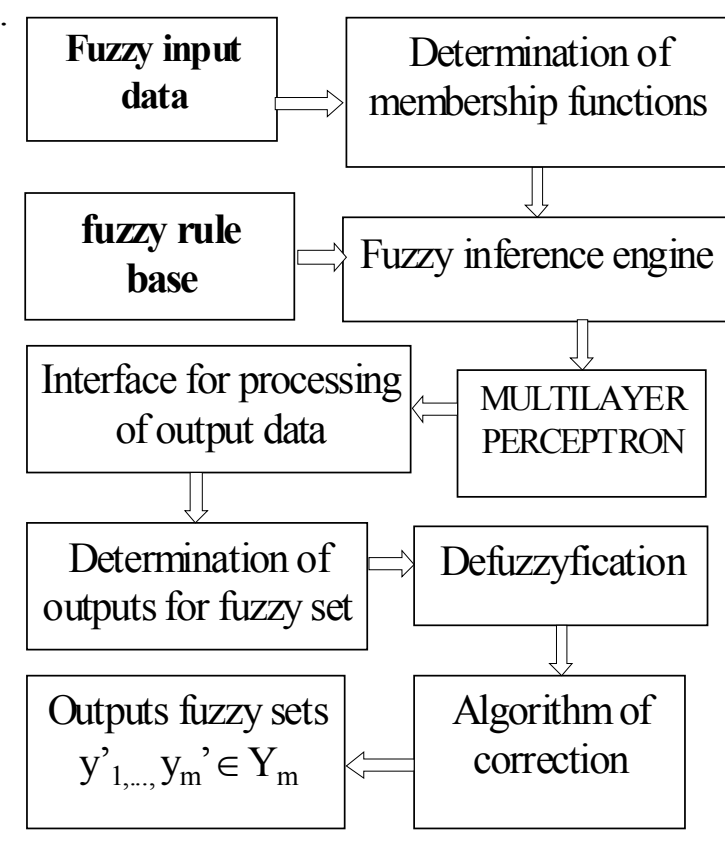

Fig. 4. Conception of fuzzy neural system.

- Assuming that $\mathrm{A}_{11}{ }^{\prime} \times \mathrm{A}_{1 \mathrm{n}}{ }^{\prime} \mathrm{x} \ldots . . \mathrm{x} \quad \mathrm{A}_{\mathrm{nk}}{ }^{\prime}=\mathrm{A}$ and $\mathrm{B}_{\mathrm{jk}}{ }^{\prime}=\mathrm{B}$, the fuzzy rules (4) and (5) can be interpreted by the product-operation rule of fuzzy implication:

$$
\mathrm{m}_{\mathrm{A} B \mathrm{~B}}\left(\mathrm{x}_{\mathrm{i}}, \mathrm{y}_{\mathrm{j}}\right)=\mathrm{m}_{\mathrm{A}}\left(\mathrm{x}_{\mathrm{i}}\right) \mathrm{m}_{\mathrm{A}}\left(\mathrm{y}_{\mathrm{j}}\right)
$$

- Each fuzzy set $\mathrm{Ai}^{\circ} \mathrm{O} \mathrm{R}\left(\mathrm{x}_{\mathrm{i}}\right)$ can be described by means of primary fuzzy sets included in the set $\mathrm{c}_{\mathrm{i}}$, and also with the use of compatibility measure of two fuzzy sets $A_{i}$ and $A_{i k}$ :

$$
\begin{aligned}
& \mathrm{p}\left(\mathrm{A}_{\mathrm{i}}, \mathrm{A}_{\mathrm{ik}}\right)=\sup \left\{\min \left[\mathrm{m}_{\mathrm{Ai}}\left(\mathrm{x}_{\mathrm{i}}\right), \mathrm{m}_{\mathrm{Aik}}\left(\mathrm{x}_{\mathrm{i}}\right)\right]\right\}, \\
& \mathrm{x}_{\mathrm{i}} \in \mathrm{X}_{\mathrm{i}}=1,2, \ldots, \mathrm{a}_{\mathrm{i}} .
\end{aligned}
$$

- If the input data is quantitative $\mathrm{x}_{\mathrm{i}}^{\prime} \mathrm{OX}$ then they are described by the membership function

$\mathrm{m}_{\underline{x} \mathbf{i}}\left(\mathrm{x}_{\mathrm{i}}\right)=1$, if $\mathrm{x}_{\mathrm{i}}=\mathrm{x}_{\mathrm{i}}^{\prime}$ and

$\mathrm{m}_{\mathrm{xi}} \cdot\left(\mathrm{x}_{\mathrm{i}}\right)=0$, if $\mathrm{x}_{\mathrm{i}}$ № $\mathrm{x}_{\mathrm{i}}^{\prime}$ (so called fuzzy singleton). Subsequently, the compatibility measure is used:

$$
\mathrm{p}\left(\underline{\mathrm{x}}_{\mathrm{i}}^{\prime}, \mathrm{A}_{\mathrm{ik}}\right)=\sup \left\{\min \left[\mathrm{m}_{\underline{\underline{x}}}{ }^{\prime}\left(\mathrm{x}_{\mathrm{i}}\right), \mathrm{m}_{\mathrm{Aik}}\left(\mathrm{x}_{\mathrm{i}}\right)\right]\right\}=\mathrm{m}_{\mathrm{Aik}}\left(\mathrm{x}_{\mathrm{i}}{ }^{c}\right)
$$

Let us transform the output data in the same way too, by means of primary fuzzy sets, the membership function, and fuzzy logic.

- Let $\mathrm{j}$ be the number of output $\mathrm{Y}_{\mathrm{j}}$ and, respectively, fuzzy sets $\mathrm{C}_{j}^{0} \mathrm{OF}\left(\mathrm{Y}_{\mathrm{j}}\right)$, which is determined by the composition "measure of activa-tion" $\left(\left\{\mathrm{v}_{\mathrm{j} k}\right\}^{\mathrm{b}}{ }_{\mathrm{jk}=1}\right)$ and composition primary fuzzy sets in the following form:

$\mathrm{m}_{\mathrm{Cj}}{ }^{0}\left(\mathrm{y}_{\mathrm{j}}\right)=\mathrm{max}\left\{\mathrm{min}\left[\mathrm{m}_{\underline{B j 1}}\left(\mathrm{y}_{\mathrm{j}}\right), \mathrm{v}_{\mathrm{j} 1}\right]\right.$, $\left.\min \left[\mathrm{m}_{\mathrm{B} j 2}\left(\mathrm{y}_{\mathrm{j}}\right), \mathrm{v}_{\mathrm{j} 2}\right], . ., \min \left[\mathrm{m}_{\underline{B} \mathrm{jk}}\left(\mathrm{y}_{\mathrm{j}}\right), \mathrm{v}_{\mathrm{jk}}\right]\right\}$,

$$
\mathrm{j}=1,2, \ldots, \mathrm{m} \text {. }
$$

\section{NEURAL NETWORK TRAINING}

A multilayer perceptron is subjected to the process of training, i.e. a classical neural network, which is a component of the fuzzy neural network model described above.

For other research $[2,3,5,7]$, the Back Propagation algorithm and its modi-fications are used for training of this neural network. As it has been known, the above-presented algorithm for network training does not guarantee the obtaining of global minimum for quality evaluation (for error). Nevertheless, in research on solving a number of practical tasks, it is possible to obtain a very exact approximation of the training data, while the training process is taking place, by execution of calculations for various parameter values $(\mathrm{h}$, a and, what is most important - the quantity of neurons in the hidden layer $-\mathrm{N}_{1}$ ), after which the optimal variant is chosen. Consequently, a conclusion may be drawn that for solving of a number of practical tasks, the obtaining of global minimum for quality evaluation is not a necessary and indispensable condition of recei-ving satisfactory results.

To avoid the problem referred to above, in this paper research on the use of genetic algorithms is carried out for solving the task of neural network training, and also for determination of the optimal topo-logical network structure. The preliminary results obtained previo-usly, as well as the data by other authors [5,7], point to the fact he use of genetic algorithms for solving such tasks is potentially a very effective research method.

\section{AN EXAMPLE OF A PRACTICAL APPLICATION OF A HYBRID EXPERT SYSTEM}

The fuzzy neural network presented above has been used for development of an intelligent decision support system. On the basis of the idea presented above, a decision support system has been implemented. The decision support system has been applied to select a product strategy in the area of household equipment.

In this paper, the selection method of marketassortment-strategy has been applied for the choice of the product development strategy. For develop-ment of the market-assort-ment-strategy basic notions of the Business Portfolio Models have been applied. Business Portfolio Models are tools for product classification used for determination of a competitive posi-tion of a business on the market, and assessment of the market possibilities. In this paper one of the most popular GE (General Electric) methods is applied, otherwise called the 
GE's Multifactor Portfolio Matrix. This approach has a variety of names, including the nine-cell GE matrix, GE's nine-cell business portfolio matrix, and the market attractiveness-business strength matrix [8]. The basic approach is shown in Fig.3.

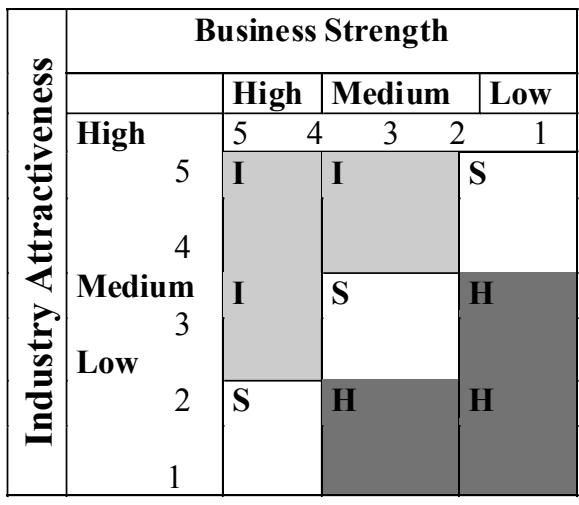

Fig.3 GE Multifactor Portfolio Matrix [8]

Each circle in this matrix represents the entire market and the shaded portion represents the organization's business market share. Each of an organization's businesses is plotted in the matrix on two dimensions, industry attractiveness and business strength. Each of these two major dimensions is a composite measure of a variety of factors. The two dimensions make good sense for strategy formulation, because a successful business is typically one that is an attractive industry and has a particular business strength required for succeeding in it. To use this approach, an organization must determine what factors are most critical for defining industry attractiveness and business strength. In this paper a list of the factors that are commonly used for placing businesses on the aforesaid dimen-sions has been used, which is presented in [8]. Depending on where businesses are plotted on the matrix, three basic strategies are formulated:

I - invest/grow, S - Selective invest-ment and $\mathrm{H}$ - Harves $\mathrm{t} /$ divest.

The next step is to weigh each variable on the basis of its perceived importance relative to the other factors (hence the total of the weights must be 1.0). Subsequently, a fuzzy-neural sys tem must indicate, on a scale of 1 to 5 , how low or high the business scores on that factor. Table 1 presents this analysis for one business.

Performance of a fuzzy neural expert system has been tested on the following input data:

- $\mathrm{N}=22$ - number neurons in input layer; $\mathrm{L}=$ 68 - rules.

- Fuzzyfication with 3 linguistic variables $-\mathrm{K}=$ 3 has been applied to the system (Fig.3).

- Number neurons in hidden layer: 10,15, 25,30,35 (Fig.5).

- Number neurons in output layer: 3.
- The fuzzy set defined in $\mathrm{R}(\mathrm{Xi})$ is characterized by a membership function $\mathrm{m}_{\mathrm{Bjk}}(\mathrm{yj}): \mathrm{R} \circledast[0,1]$, and is labeled by a linguistic term $\mathrm{A}_{\mathrm{ik}}$, such as "high", "medium", "low" (industry attractiveness and busi-ness strength). The membership function for the fuzzy set inputs, is shown in Fig.4.

Table 1. Illustration of Industry Attractiveness and Business Strength Computations (source [8])

\begin{tabular}{|l|c|c|}
\hline \multicolumn{1}{|c|}{$\begin{array}{c}\text { Industry } \\
\text { Attractiveness }\end{array}$} & Weight & Value \\
\hline Overall market size & 0,20 & 0,8 \\
\hline $\begin{array}{l}\text { Annual market growth } \\
\text { rate }\end{array}$ & 0,20 & 1,0 \\
\hline $\begin{array}{l}\text { Historical profit } \\
\text { margin }\end{array}$ & 0,15 & 0,6 \\
\hline Competitive intensity & 0,15 & 0,45 \\
\hline $\begin{array}{l}\text { Technological } \\
\text { requirements }\end{array}$ & 0,15 & 0,45 \\
\hline $\begin{array}{l}\text { Inflationary } \\
\text { vulnerability }\end{array}$ & 0,05 & 0,10 \\
\hline Energy requirements & 0,05 & 0,15 \\
\hline Environmental impact & 0,05 & 0,05 \\
\hline Social/political/legal & $\begin{array}{c}\text { Must be } \\
\text { accetable } \\
1,00\end{array}$ & 3,60 \\
\hline
\end{tabular}

\begin{tabular}{|c|c|c|}
\hline Business strength & Weight & Value \\
\hline Market share & 0,10 & 0,40 \\
\hline Share growth & 0,15 & 0,60 \\
\hline Product quality & 0,10 & 0,40 \\
\hline Brand reputation & 0,10 & 0,50 \\
\hline Distribution network & 0,05 & 0,20 \\
\hline $\begin{array}{l}\text { Promotional } \\
\text { effectiveness }\end{array}$ & 0,05 & 0,25 \\
\hline Productive capasity & 0,05 & 0,15 \\
\hline Productive effeciency & 0,05 & 0,10 \\
\hline Unit costs & 0,15 & 0,45 \\
\hline Material supplies & 0,05 & 0,25 \\
\hline R\&D performance & 0,10 & 0,40 \\
\hline \multirow[t]{2}{*}{ Managerial personnel } & 0,05 & 0,20 \\
\hline & 1,00 & 4,10 \\
\hline
\end{tabular}

A fuzzy neural network accepts both quantitative and qualitative information in the learning data set. Qualitative information is represented by the fuzzy set apparatus in the form of an appropriate set of membership functions for each linguistic variable.

In the case of the generation of quantitative output data, defuzzy-fication is carried out with the use of the center average method:

$$
\mathrm{y}_{\mathrm{j}}^{0}=\frac{\sum_{\mathrm{j}=1}^{\mathrm{m}} \overline{\mathrm{y}} \mu_{\mathrm{b}_{\mathrm{j}}}(\overline{\mathrm{y}})}{\sum_{\mathrm{j}=1}^{\mathrm{m}} \mu_{\mathrm{b}_{\mathrm{j}}}(\overline{\mathrm{y}})}
$$




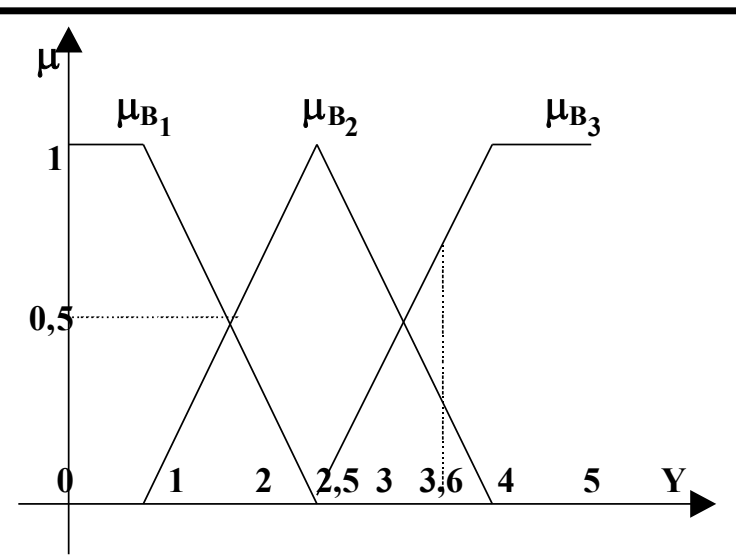

Fig.3. Membership function for the inputs fuzzy set

During the system testing, mean absolute error was used as a criterion of quality evaluation and the assessment of the system, which for the training data assumes the form:

$$
\left.\mathrm{Q}=\frac{1}{\mathrm{PM}} \sum_{\mathrm{p}=1}^{\mathrm{P}} \sum_{1=1}^{\mathrm{M}-1}\left(\mathrm{~d}_{1}^{\mathrm{p}}-\mathrm{v}\right)^{\mathrm{p}}\right)^{2}, \mathrm{p}=1,2, \ldots \mathrm{P}
$$

Another such criterion of system as sessment with respect both to the training and testing data is the maximum system error $\mathrm{Q}_{\mathrm{BMax}}$, defined as follows:

$$
\mathrm{Q}_{\mathrm{B}_{\mathrm{Max}}}=\max _{\substack{\mathrm{p}=1,2, . . \mathrm{P} \\ \mathrm{L}=0,1, \ldots, \mathrm{M}-1}}\left|\mathrm{~d}_{1}^{\mathrm{p}}-\mathrm{v}_{1}^{\mathrm{p}}\right|
$$

The results of simulation researches shown on Fig.5

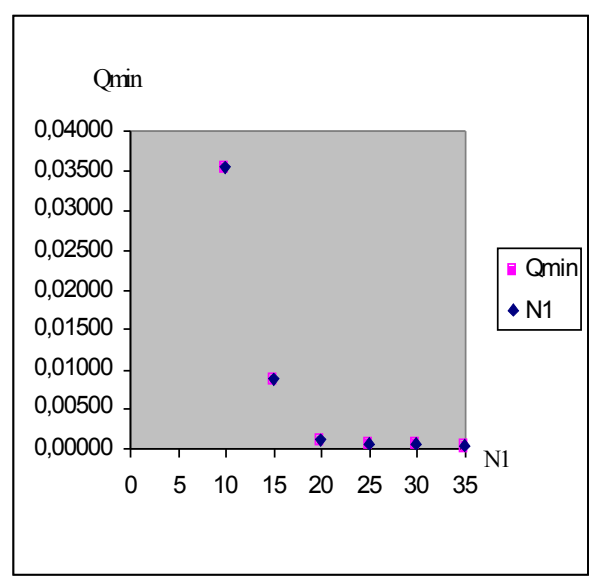

Fig.5 Results of training phase for fuzzy

\section{Conclusions.} neural network

In the study, the fuzzy neural network, based on multilayer percep-tron and fuzzy sets theory was presented. Fuzzy neural networks are a universal theoretical instrument for complex processes modeling and for developing intelligent decision sup-port systems, characterized by the ability to process quantitative, as well as qualitative, and lin- guistic infor-mation, and thus to solve unstructured tasks in a fuzzy environment. Fuzzy neural network models show very good features for interpolation and extrapolation of training data used during the training process. The research conducted proves that fuzzy neural networks are a very effective and useful instrument of implemen-tation of intelligent managerial systems.

\section{REFERENCES}

[1] M.Gorczaiczany: Fuzzy neural networks in expert systems and in process modeling, (in pol.), Kielce, 1993, pp.147.

[2] M. Brown and Chris Harris. Neurofuzzy Adaptive Modelling and Control, Prentice Hall, New York, 1994, p. 274.

[3] J.J. Buckley, Y. Hayashi: Fuzzy neural networks: A survey, Fuzzy Sets and Systems, vol.66, 1994, pp.l-13.

[4] Zadeh L.A.: Fuzzy sets as a basis for a theory of possibility. Fuzry sets and Systems, $\mathrm{Nl}$, 1978, pp. 3-28.

[5] Rutkowska D.: Inteligentne sys-temy obliczeniowe, Akademicka Ofi-cyna Wydawnicza PLJ, Warszawa, 1997, pp. 304.

[6] Setlak G. Neural networks in the Intelligent Infor-mation Systems of Management, «Journal of Auto-mation and Information Sciences», Kiev, N1, 2000r., pp. 112-119.

[7] Schaffer J.D., Whitley L. Eshelman J.: Combinations of Genetic Algorithms and Neural Networks: A Survey of the State of the Art., Proceed. of International Workshop "Combinations of Genetic Algorithms and Neural Networks", COGANN-92,1992, pp. 244-248.

[8] C. Samuel Certo, J.Paul Peter: Strategic Management, Random House, Inc., New York, 1988, pp. 1203.

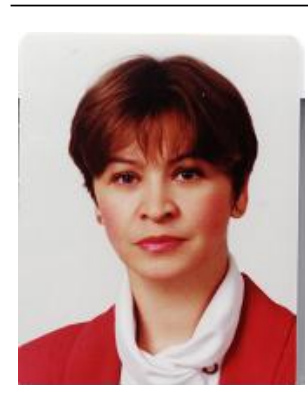

Galina Setlak received the Master's degree in Computer Engineering and Systems Analysis in 1977 and the PhD degree in Computer Science from the Technical University of Kharkov in 1994. From October 1980 She is scientific worker in the Technical University of Rzeszow, Poland. She is currently Assistant Professor in the Department of Computer Science at the Technical University of Rzeszow.

Her research interests include decision-making in intelligent information systems, artificial Intelligence, neural networks, fuzzy logic, soft computing. She has published over 35 journal papers in the areas decision-making in manufacturing systems, soft computing and neural networks. 